\title{
Post Traumatic Stress Disorder/PTSD in adolescent victims of sexual abuse: resilience and social support as protection factors
}

\author{
Síndrome do Estresse Pós-Traumático/PTSD \\ em adolescentes vítimas de violência sexual: \\ a resiliência e o suporte social como fatores de proteção
}

Martine Hébert ${ }^{1}$

Francine Lavoie ${ }^{2}$

Martin Blais ${ }^{1}$

'Département de Sexologie, Université du Québec à Montréal. succ. 8888 Centre-Ville Montréal H3C 3P8 Canada. hebert.m@uqam.ca 2École de psychologie, Université Laval.
Abstract This analysis examined the contribution of personal, family (maternal and paternal support; sibling support) and extra-familiar (peer support; other adults) resilience to the prediction of clinical levels of PTSD symptoms in adolescents reporting sexual abuse. Controls were established for abuse-related variables (type of abuse, severity and multiple abuse) in a representative sample of high schools students in the province of Quebec. A total of $15.2 \%$ of adolescent females and 4.4\% adolescent males in high school reported a history of sexual abuse in childhood. Sexually abused adolescent females $(27.8 \%)$ were more $i$ kely than adolescent males (14.9\%) to achieve scores with high clinical levels of PTSD. Hierarchical logistic regression revealed that over and above the characteristics of the sexual abuse experienced, resilience factors (maternal and peer support) contributed to the prediction of symptoms of PTSD attaining the clinical threshold. Alternative intervention and prevention practices geared to adolescent victims of sexual assault are discussed.

Key words Resilience, Sexual abuse in childhood, PTSD, Protection factors, Maternal and peer support
Resumo A presente análise explorou a contribuição da resiliência pessoal, familiar (apoio maternal e paternal, o apoio irmão) e extra-familiar (apoio dos pares, outro adulto) para a previsão de níveis clinicos de sintomas de Síndrome do Estresse Pós-Traumático (PTSD) em adolescentes que relataram abuso sexual, controlando-se variáveis relacionadas com o abuso (tipo de abuso, gravidade e abuso múltipla) em amostra representativa de alunos das escolas da província de Quebec. O total de 15,2\% das meninas e 4,4\% dos meninos do ensino médio relataram uma história de abuso sexual infantil. Meninas abusadas sexualmente $(27,8 \%)$ eram mais propensas, comparadas aos meninos (14,9\%), para obter pontuação atingindo níveis clínicos de PTSD. A regressão logística hierárquica revelou que, para além das características do abuso sexual sofrido, fatores de resiliência (suporte materno e apoio dos pares) contribuíram para a predição de sintomas de PTSD que atingiram o limite clínico. São discutidas alternativas práticas de intervenção e de prevenção direcionadas a adolescentes vítimas de abuso sexual.

Palavras-chave Resiliência, Abuso sexual infantil , PTSD, Fatores de proteção, Suporte materno e dos pares 


\section{Introduction}

Child sexual abuse is an important social problem internationally. A meta-analysis of 217 publications from different countries published between 1980 and 2008 estimated the prevalence rate of sexual abuse before the age of 18 at $18 \%$ among women and $7.6 \%$ among men ${ }^{1}$. The majority of published studies have focused on the identification of long-term symptoms of child sexual abuse experienced with retrospective studies relying on adult samples. The results indicate unequivocally that child sexual abuse is linked to multiple long-term consequences. Indeed, reviews of the scholarly literature conclude that childhood sexual abuse is a non-specific risk factor for a spectrum of psychological disorders, including depression, suicidal ideations, anxiety disorders and post-traumatic stress disorder (PTSD), as well as physical health problems and at-risk sexual behaviors $^{2-4}$. The association between child sexual abuse and negative outcomes is found to persist even after controlling for other adverse factors in childhood such as physical abuse, problematic parent-child attachment, and parental history of illicit drug use $\mathrm{s}^{5,6}$.

Despite the proliferation of studies on this subject over the past 30 years, our knowledge of the short-term consequences among youth having experienced sexual abuse remains limited. Hence, relatively little is known about victims' trajectories once they enter adolescence, a pivotal time in which they are confronted with important developmental tasks. The available studies highlight the negative sequelae associated with a history of sexual abuse among adolescents. Indeed, adolescents recruited in intervention and treatment centers following disclosure show high levels of psychological distress ${ }^{7,8}$. Studies highlight the presence of significant dissociation symptoms $s^{9}$ and externalized behavior problems (conduct disorder, drug abuse, delinquency) $)^{5}$, as well as risky sexual behaviors (early onset of first sexual relations, increased number of sexual partners, unprotected sex $)^{10}$ in sexually abused adolescents. Research also suggests that, during adolescence, victims of sexual abuse present a considerable risk for suicidal ideations or attempted suicides $^{7,11}$ as well as victimization in the context of their romantic relationships ${ }^{12,13}$.

Over and above the diverse consequences associated with child sexual abuse, PTSD appears to be one of the constellations of symptoms most frequently experienced by victims of sexual abuse $^{14}$. The diagnostic criteria of post-traumat- ic stress disorder is defined by symptoms of intrusion, avoidance of stimuli related to the trauma and hyperarousal. A review of studies published between 2000 and 2011 on post-traumatic stress disorder during adolescence revealed that $57 \%$ of teenagers who experienced a sexual trauma had PTSD ${ }^{15}$. In: fact, one of the first reviews of empirical studies - whose main conclusions remain valid - stated that PTSDis one of only two typical manifestations observed among young victims of sexual abuse incomparison to other clinical populations ${ }^{16}$.

Yet, one of the findings that still challenge researchers in the field relates to the vast diversity of profiles in child sexual abuse victims and the identification of possible risk and protective factors involved. Clinicians and child welfare workers deal with a wide array of cases illustrating situations that may range from a single fondling episode to complete intercourse, involving a stranger, a known adult, a close family member or a caregiver. Factors related to the sexual abuse experienced may influence the presence and the intensity of PTSD symptoms. Indeed, characteristics of the traumatic event (duration, severity and relationship to the perpetrator)seem to play a role in the intensity of PTSD symptoms ${ }^{17}$. Thus, sexual abuse that is chronic, very severe (with penetration or attempted penetration) or involving the use of force is linked to greater PTSD symptoms ${ }^{18,19}$.

Not only do youths experience quite diverse situations of sexual abuse but it is also highly improbable that all have the same personal competencies to deal with the trauma and that all benefit from the same family environment or extra-familial network to help them in this task. As for personal factors, a high level of resilience may act as a protective factor against psychological distress and PTSD symptoms. While various definitions of resilience have been proposed, resilience is generally considered as the capacity to overcome adversity ${ }^{20}$.

In exploring other variables that might be reliably linked to differential outcomes, researchers have identified a supportive stance from the nonoffending parent as a potential factor. Support from the non-offending parent may serve as a buffer against detrimental outcomes following disclosure and a positive relationship to parental figures may play a crucial role in how survivors cope with the sexual abuse both in the short and long-term ${ }^{21-23}$. Thériault et al. ${ }^{24}$ contrasted the predictive value of both general maternal support and specific maternal supportive reaction to the 
disclosure. Interestingly, results revealed that general maternal support was a better predictor of outcomes than specific maternal supportive reactions to the disclosure (i.e. believing the child, taking action to protect against further abuse and soliciting appropriate services to foster the child's recovery). The few available follow-up studies suggest that lack of social support at initial evaluation contributes to greater internalizing symptoms in sexually abused adolescents six months later ${ }^{25}$. In: addition, youths reporting high caregiver support initially report higher self-esteem and less depression one year later ${ }^{23}$.

In time of adversities, siblings can also reveal to be an important source of assistance and emotional support. Positive relationships with siblings may promote emotion regulation strategies that in turn reduce the risk of developing internalized or externalized behavior problems ${ }^{26}$. Jenkins $^{27}$ found that having a close relationship with a sibling acted as a protective factor for children from disharmonious homes. Other studies have found that youth with supportive relationships with siblings report less depressive symptoms $^{28}$ and for youth living in high conflict families, the support received from siblings was related to adjustment ${ }^{29}$. A recent meta-analysis of 34 studies reveals that sibling warmth and less conflict with sibling are associated with lower internalized and externalized behavior problems ${ }^{26}$. The protective function of a close and positive relationship with a sibling for SA victims' adaptation has rarely been considered; still one study found that children reporting a warm and positive relationship with a sibling were rated as displaying less sexualized behaviors ${ }^{30}$.

From an eco-systemic perspective, besides personal and family factors, different resources found outside of the family environment (peers, significant adults, community, etc.) have the potential to act as protective factors for youth facing adverse life events ${ }^{31}$. Peers can offer considerable support to victims, given their increasing important role in adolescence. In comparison to children, teenage victims of sexual abuse may be more susceptible to confide in their peers. In fact, in one study of adolescents, the most common recipient of disclosure of sexual abuse was a friend and nearly $40 \%$ had only disclosed to a same-age peer and nobody else ${ }^{32}$. Feelings of support in relationships with significant peers may buffer feelings of distress and teenagers with secure attachment to peers are found to be less depressed and anxious ${ }^{33}$. Youth living in disharmonious homes may also be more likely to turn to peers for emotional support, especially if the sexual abuse involves a family member and emotional support is not available in the familial environment. Few studies have considered extrafamilial variables as potential factors associated to the severity of symptoms experienced by sexually abused victims. However, one study suggests that peer support is not necessarily beneficial and in fact, may be associated with PTSD symptoms and negative self-perception ${ }^{34}$.

In sum, personal, familial and extra-familial factors may influence outcomes in teenagers reporting sexual abuse. The majority of studies conducted up to now have relied on clinical samples or samples of victims under child protection service care. Notwithstanding the wealth of information provided, findings regarding child protective services cases may not reflect the high proportion of cases that are not reported to such authorities and might actually cover only the more severe cases. In: this context, the present study aims to explore the potential contribution of personal, familial and extra-familial factors to the prediction of clinical levels of PTSD symptoms, while controlling for abuse-related characteristics in teenagers reporting sexual abuse recruited as part of a large representative sample of 14-18 years old high school students in Quebec. Given that past studies have identified gender and age as potential factor linked to PTSD ${ }^{15}$, these variables are also included in our analyses. One distinctive feature in the present study is to evaluate maternal support distinctively from paternal support as one recent study found that support from each parental figure may independently contributed to outcomes in a sample of sexually abused victims ${ }^{35}$.

\section{Method}

\section{Sample and procedure}

Data for this study are drawn from the Quebec Youths' Romantic Relationships survey. Data were collected among youths enrolled in secondary 3 to 5 through a one-stage stratified cluster sampling of 34 Quebec high schools. The questionnaire included self-reported measures on a variety of dimensions relevant to the study of victimization and took approximately $40 \mathrm{~min}$ utes to complete. The research ethic boards of the Université du Québec à Montréal approved this project. Participants agreed to participate on a voluntary basis by signing a consent form. 
To correct biases in the non-proportionality of the schools sample compared to the target population, participants were given a sample weight defined as the inverse of the probability of selecting the given grade in the respondent's stratum in the sample multiplied by the probability of selecting the same grade in the same stratum in the population. No additional adjustment was made for non-response given the response rate of nearly $100 \%$ among students. The total unweighted sample consisted of 8194 participants and the final weighted sample size was 6540 .

For most questions, the rate of partial nonresponse was less than $3.5 \%$. Analyses of the nature of partial non-response did not show presence of specific patterns of non-response. To minimize the effect of partial non-response, multiple imputations of missing data were used for variables with a non-response rate of less than $5 \%$. The multiple imputations were conducted using SPSS 20.0. Seven imputed databases were created. The present analyses will focus on the sample of high school girls ( $n=573)$ and boys $(n=121)$ that reported a history of child sexual abuse. Of the respondents, $88.8 \%$ reported French as the main language spoken at home and that $78.9 \%$ of theirs mothers and $87.1 \%$ of their fathers were presently employed. Close to half of the participants $(50.5 \%)$ lived with both parents, while $40.9 \%$ lived either in single-parent families or in shared custody and 7.8\% described another family arrangement (living with a member of the extended family, in foster care, etc.).

\section{Measures}

Participants were invited to complete a series of self-report measures pertaining to sexual abuse experiences, PTSD symptoms and potential protective factors (resilience and perceived social support).

Sexual abuse. A series of questions evaluated the presence of sexual abuse derived from measures used in past studies ${ }^{36,37}$. Two questions refereed to unwanted sexual contact, one regarding contact without penetration such as fondling and touching, and the other to forced sex involving penetration (oral, anal, vaginal). Prevalence of child sexual abuse was defined as a positive response to either question and items refer to incidents occurring in the course of their lives. When a participant responded affirmatively to either question, they were then asked to specify whom the situation involved. In the present analysis, answers indicating an intra-familial perpetrator were coded as 1 for answer and 0 when participants identified known assailant outside the family or unknown assailant. The sexual abuse measure excluded sexual coercion involving a romantic partner. For the purpose of the analysis, a variable was also coded to identify severity of sexual abuse ( 0 . No penetration and 1 . Penetration) and whether or not more than one situation of sexual abuse was reported.

PTSD symptoms. The Abbreviated University of California at Los Angeles PTSD Reaction In$\operatorname{dex}^{38}$ (A-UCLA-PTSD-RI)evaluates PTSD symptoms in the past month. The measure involved 9 items (for instance, I get upset, afraid or sad when something makes me think about what happened) and a 5-point frequency response scale varying from "None" to "Most". A score of 10 or higher is considered to reflect clinically significant PTSD symptoms. Steinberg et al. ${ }^{39}$ report a high internal consistency of the abbreviated scale $(\alpha=.87)$.

Resilience. An abbreviated form of the Connor-Davidson Resilience Scale (CD-RISC2) ${ }^{40}$ is used to evaluate resilience. Two items are completed with a 5-point Likert scale ("False", "Mostly False", "Sometimes false/sometimes true", "mostly true"and"True"). Vaishnavi et al. ${ }^{40}$ report adequate psychometric properties (test-retest reliability, convergent and discriminant validity) of the CD-RISC2. They further argue that the abbreviated form is representative of the original CD-RISC ${ }^{20}$ as significant correlations are obtained between the CD-RISC2 and the CD-RISC total score $(r=.78)$ and with the other 23 items of CD-RISC (ranging from $r=.27$ to $r=.66$ ).

Maternal and paternal support. Perception of maternal and paternal support was evaluated by means of a scale of 6 items ( 3 items for maternal support and 3 items for paternal support). These items are derived from the "Teen Assessment Project" (TAP) cited in Banyard and Cross' study ${ }^{41}$. The items (for eg., My mother cares about me) are completed with a 5-point Likert scale varying from "Never" to "Very often" and referred to the past 12 months. In the TAP study, authors report that the internal consistency of the parental support scale was adequate $(\alpha=.83)$.

Sibling support, peer support and support from an extra-familial adult. Three indicators serve to measure general perceived support from siblings, from peers and from a trusted extra-familial adult. Items were derived form the Enquête sociale et de santé auprès des enfants et des adolescents $^{42}$ and refer to the availability of individuals to help in case of need. The 3-point response scale varied "Not at all" to "A lot". 
Results will be presented in three sections. First, descriptive results concerning the sexual abuse experienced by teenagers will be reported. Second, analysis exploring the association of abuserelated variables and PTSD symptoms will be presented. Finally, the results of the logistic regression exploring the possible contribution of personal, familial and extra-familial factors to PTSD symptoms will be described.

\section{Descriptive data \\ on sexual abuse experienced}

Overall in our sample, $15.2 \%$ of girls and $4.4 \%$ of boys reported having experienced child sexual abuse including touching and/or penetration. Among teenagers reporting sexual abuse, 58.6\% of cases reported the abuse involved touching or fondling, $10.1 \%$ reported the abuse involved penetration acts while close to a third of teenagers (31.3\%) reported both touching and penetration. A total of $42.2 \%$ of victims reported experiencing more than one episode of sexual abuse involving different perpetrators. The different perpetrators involved are reported in Table 1.

\section{Abuse-related characteristics associated with PTSD symptoms}

In our sample, $14.9 \%$ of sexually abused boys and $27.8 \%$ of sexually abused girls achieved a clinical score of PTSD symptoms. $\left(\chi_{(1)}^{2}=9.20, p<\right.$ $0.002)$. Chi-square analyses were conducted to explore whether severity of acts involved and type of sexual abuse were linked to PTSD symptoms reaching clinical levels. Results revealed that severity of the abuse was significantly associated to PTSD symptoms as a greater proportion of victims reporting penetrative acts reached clinical levels of symptoms (30.9\%) compared to victims reporting touching $(22.1 \%)\left(\chi_{(1)}^{2}=9.93, p\right.$ $<0.002)$. The analysis failed to identify a significant association between type of sexual abuse (intra- or extra-familial abuse) and PTSD symptoms as the prevalence of clinical levels of symptoms is similar for teenagers reporting abuse involving a family member $(26.3 \%)$ and teenagers abused by a extra-familial perpetrator (25.2\%) $\left(\chi_{(1)}^{2}=1.51, n s\right)$. However, teenagers reporting more than one CSA were more likely to achieve clinical levels of PTSD symptoms (34.7\%) compared to those reporting only one situation of $\operatorname{CSA}(18.8 \%)\left(\chi_{(1)}^{2}=22.03, p<0.000\right)$.

\section{Regression analysis}

Means and standard deviation of scores on the personal (resilience), family (maternal and paternal support, sibling support) and extra-familial variables (other adult, peer support) are presented in Table 2. Overall, teenagers reported higher level of maternal support $(M=8.75, S D=$ 3.70) than paternal support $(M=6.83, S D=4.20)$ $\left(t_{(693)}=11.50, p<0.000\right)$. Results also revealed that teenagers perceived greater support from peers $(M=2.68, S D=0.60)$ than from sibling $(M$ $=1.85, S D=1.02)\left(t_{(693)}=20.56, p<0.000\right)$.

A hierarchical logistic regression analysis was conducted to evaluate the contribution of personal, familial and extra-familial factors to the

Table 1. Type of Sexual Abuse Experienced and Perpetrators Involved.

\begin{tabular}{lccc}
\hline & Girls & Boys & Total \\
\hline Touching & $(n=543)$ & $(n=100)$ & $(n=643)$ \\
$\quad$ Intra-familial & $(n=156) 28.7 \%$ & $(n=23) 23.0 \%$ & $(n=179) 27.8 \%$ \\
$\quad$ Known assailant & $(n=353) 65.0 \%$ & $(n=75) 75.0 \%$ & $(n=428) 66.6 \%$ \\
$\quad$ Unknown assailant & $(n=143) 26.3 \%$ & $(n=32) 32.0 \%$ & $(n=175) 27.2 \%$ \\
Penetration & $(n=215)$ & $(n=51)$ & $(n=266)$ \\
$\quad$ Intra-familial & $(n=70) 32.6 \%$ & $(n=16) 31.4 \%$ & $(n=86) 32.3 \%$ \\
$\quad$ Known assailant & $(n=140) 65.1 \%$ & $(n=39) 76.5 \%$ & $(n=179) 67.3 \%$ \\
$\quad$ Unknown assailant & $(n=61) 28.4 \%$ & $(n=22) 43.1 \%$ & $(n=83) 31.2 \%$ \\
Touching and/or penetration & $(n=173) 30.2 \%$ & $(n=32) 26.5 \%$ & $(n=694)$ \\
$\quad$ Intra-familial & $(n=382) 66.7 \%$ & $(n=92) 76.0 \%$ & $(n=474) 68.3 \%$ \\
$\quad$ Known assailant & $(n=166) 29.0 \%$ & $(n=46) 38.0 \%$ & $(n=212) 30.6 \%$ \\
$\quad$ Unknown assailant & & $(n=121)$ & $(n=5 \%)$
\end{tabular}

Fuente: Elaboración propia a partir de datos del Sistema Nacional de Información en Salud (SINAIS), el Instituto Nacional de Estadística, Geografía e Informática (INEGI) y el Consejo Nacional de Población (CONAPO). 
prediction of PTSD reaching clinical levels, while controlling for socio-demographic variables (age and gender) and abuse-related characteristics. The analysis was conducted using the direct-entry method to allow us to evaluate the unique contribution of each predictor beyond that of other predictors. Results of the logistic regression for the prediction of clinical-level PTSD symptoms reached significance level $\left(\chi_{(11)}^{2}=\right.$ 285.39, $p<0.001$ ) (Cox \& Snell $R^{2}=0.31$; Nagelkerke $\left.R^{2}=0.41\right)$. Results at the last step of the regression are presented in Table 3. As for socio-demographic variables, girls are found more likely to display significant PTSD symptoms. In addition, older teenagers are at increasing odds of presenting clinical level of PTSD symptoms. Results indicate that reporting more than one situation of sexual abuse is associated with higher likelihood or presenting clinical level of PTSD symptoms. This variable increased the odds of presenting PTSD symptoms reaching clinical levels by more than threefold.

Among other variables providing a unique contribution to the prediction of PTSD symptoms is resilience. Thus, sexual abuse teenagers

Table 2. Range of Score and Means (SD) for Study Variables.

\begin{tabular}{lccc}
\hline \multicolumn{1}{c}{ Variables } & Range & \multicolumn{2}{c}{ Mean SD } \\
\hline Resilience & $0-8$ & 5.27 & 1.96 \\
Maternal support & $0-12$ & 8.76 & 3.70 \\
Paternal support & $0-12$ & 6.83 & 4.20 \\
Sibling support & $0-3$ & 1.85 & 1.02 \\
Friend support & $0-3$ & 2.68 & 0.60 \\
Other adult support & $0-3$ & 1.71 & 0.99 \\
\hline
\end{tabular}

with high resilience scores were less likely to report PTSD in the clinical range. Finally, high perceived maternal support as well as peer support, were found to be associated with a decrease likelihood of presenting PTSD symptoms reaching clinical levels in sexually abused teenagers. In the present analysis, paternal or sibling support and support from an extra-familial individual did not uniquely contribute to the severity of PTSD symptoms in teenagers reporting sexual abuse.

\section{Discussion}

Our aim was to explore the possible contribution of personal, familial and extra-familial factors in influencing outcomes in teenagers reporting sexual abuse, more specifically in terms of PTSD symptoms. The asset of the present study was to rely on a large representative sample of high school students in Quebec; the bulk of past studies having been conducted with clinical samples or samples of victims under child protection service care which may be biased towards more severe cases.

Results of the present study confirmed that unfortunately a significant proportion of youth have experienced child sexual abuse with girls more likely than boys to report sexual trauma. Our prevalence rates of $15 \%$ in girls and $4 \%$ of boys are quite high given that teenagers were questioned and also that our inquiry specifically focused on sexual abuse and not on sexual coercion perpetrated by a dating partner.

Our data further indicates that an important number of teenagers who are victims of sexual abuse display PTSD symptoms (25.5\%). Thus the rate of symptoms reaching a clinical threshold

Table 3. Logistic Regression to Predict PTSD Symptoms Reaching Clinical Levels.

\begin{tabular}{lrrrrrrr}
\hline \multicolumn{1}{c}{ Predictors } & $\boldsymbol{B}$ & SE & Wald & dl & $\boldsymbol{p}$ & Odds ratio & {$[\mathbf{9 5 \%} \mathbf{C I}]$} \\
\hline Age & 0.08 & 0.03 & 7.42 & 1 & $\mathbf{0 . 0 0 7}$ & 1.09 & {$[1.02-1.16]$} \\
Sex & -0.93 & 0.30 & 9.77 & 1 & $\mathbf{0 . 0 0 2}$ & 0.39 & {$[0.22-0.71]$} \\
Severity of sexual abuse & -0.37 & 0.30 & 1.49 & 1 & 0.222 & 0.69 & {$[0.38-1.25]$} \\
Type of abuse & -0.19 & 0.23 & 0.64 & 1 & 0.423 & 0.83 & {$[0.52-1.31]$} \\
More than one CSA & 1.13 & 0.31 & 15.96 & 1 & $\mathbf{0 . 0 0 0}$ & 3.10 & {$[1.68-5.77]$} \\
Resilience & -0.13 & 0.05 & 6.90 & 1 & $\mathbf{0 . 0 1 0}$ & 0.88 & {$[0.80-0.97]$} \\
Peer support & -0.33 & 0.16 & 4.51 & 1 & $\mathbf{0 . 0 3 4}$ & 0.72 & {$[0.53-0.98]$} \\
Maternal support & -0.12 & 0.03 & 20.07 & 1 & $\mathbf{0 . 0 0 0}$ & 0.89 & {$[0.84-0.94]$} \\
Paternal support & -0.02 & 0.03 & 0.84 & 1 & 0.360 & 0.98 & {$[0.93-1.03]$} \\
Support from other adult & 0.01 & 0.10 & 0.01 & 1 & 0.918 & 1.01 & {$[0.83-1.23]$} \\
Sibling support & 0.05 & 0.10 & 0.27 & 1 & 0.605 & 1.06 & {$[0.86-1.29]$} \\
\hline
\end{tabular}


for sexually abused teenagers clearly exceeds the prevalence rates found in normative samples. For example, with a representative sample of American teenagers, Kilpatrick et al. ${ }^{43}$ found that the prevalence rate for PTSD among girls between the ages of 12 and 17 years to be of $6.3 \%$ and $3.7 \%$ for boys, while in their review Nooner et al. ${ }^{15}$ report an average rate of PTSD in teenagers of $14 \%$.

In analyzing possible socio-demographic factors related to significant PTSD symptoms, some authors have argued that younger teens may be more vulnerable to PTSD symptoms given their less mature emotional, cognitive and social capacities ${ }^{15}$. Yet, our data suggest instead that older teenagers were more likely to display clinical levels of PTSD symptoms. This finding may be related to older teens being more exposed to trauma and adverse life events compared to younger teenagers. In the present study, we found girls more likely to achieve clinical levels of symptoms of intrusion, avoidance of stimuli related to the trauma and hyperarousal. This result contrasts with the conclusions of a recent meta-analysis that did not detect a gender difference in lifetime risk of PTSD among survivors of childhood sexual abuse ${ }^{44}$. Maikovich et al. ${ }^{45}$ also failed to identify a significant gender difference in victims' posttraumatic stress symptoms in youths aged 8-16 years reported for alleged sexual abuse. Differences relating to the measures of PTSD and the specific cut-off points used may account for this disparity in results. Clearly these contradictory results as well as the few studies currently available call for further investigation into the gender specificities in trajectories of PTSD symptoms in sexually abused teenagers.

In examining the possible impact of abuserelated variables, only severity of abuse was found associated with PTSD symptoms in bivariate analysis, suggesting the teenagers reporting penetration were more likely to display clinical symptoms. However, the influence of severity failed to reach significance in the multivariate analysis. Indeed, the only abuse-related variable that independently contributed to the prediction of PTSD was experiencing more than one situation of sexual abuse. Thus, this variable was found to be associated with a three-fold increase in the risk for clinical level of PTSD symptoms, highlighting the cumulative effect of experiencing multiple sexual traumas. As for personal factors, teenagers describing themselves as resilient or capable to bounce back from challenges were found at lower risk of displaying significant PTSD symptoms.
Over and above socio-demographic variables, characteristics of the abuse experience and resilience features, our data confirms prior results attesting that perceived maternal support is associated with PTSD. Thus, teenagers describing their maternal figure as not available during the last 12 months preceding the survey in times of need and/or of not providing sufficient care are more likely to achieve clinical levels of PTSD. Paternal support did not prove to predict teenagers' symptoms in the present study. A number of issues will need to be considered in future studies; namely the relevance of distinguishing perceived paternal support in cases where the father is the perpetrator. Our analysis also failed to identify a distinct contribution of sibling support, which may be linked to the developmental phase of participants. Indeed, past studies identified a stronger effect of sibling support for children than for adolescents ${ }^{26}$. As children enter adolescence, peers may indeed become increasingly important in youth's lives ${ }^{46,47}$. In the present study, teenagers did report higher level of support from friends than from siblings. When controlling for sociodemographic variables as well as characteristics of the sexual abuse experienced, a high level of perceived support from friends was found to predict lower risk of PTSD. Thus feelings of support in close relationships with peers may buffer symptoms in sexually abused teenagers.

Some limits of the present study need to be acknowledged. First, the transversal design of the study does not allow for the exploration of sequencing of intervening variables. Future studies will need to rely on a longitudinal design to better document the trajectories of PTSD symptoms in teenagers reporting child sexual abuse over time. Such an approach will allow documenting whether the higher prevalence of PTSD in girls is also evident in follow-up measures. Second, the measures evaluating social support used in the present study remain based on a rather limited set of indicators. Social support is clearly a multidimensional construct and unfortunately the different functions of social support (instrumental, emotional, informational, etc.) were not integrated in the present analysis. In a study of adult females reporting child sexual abuse, self-esteem support - perception that others valued the survivor - was found to be the most predictive of low PTSD symptoms ${ }^{48}$. In addition, the present study did not disentangle important factors that may influence the role of sibling support, namely sibling gender combination as well as age difference between siblings ${ }^{26}$. Moreover, future studies 
may gain by documenting whether the sheer presence of a sibling is a potent variable influencing outcomes. Finally, the present analyses did not explore the complex interplay between gender, resilience and support and future investigations will need to do so.

In conclusion, our results underscore the diversity of outcomes in teenagers reporting child sexual abuse; a diversity that appears to be associated with resilience capacity and perceived maternal and peer support. Our results highlight some important practical implications for the evaluation of sexually abused teenagers. Clearly, the focus on abuse-related variables (for instance intra- or extra-familial abuse) is not sufficient to orient or prioritize services for vulnerable youth. A throughout and detailed evaluation not only of PTSD symptoms, but also of personal, familial and extra-familial resources and protective factors is clearly required to orient teenagers to services well-adapted to their needs. Our results also attest to the importance of not only designing efficient intervention for teenagers to help them cope with the aftermaths of sexual abuse but also to offer assistance to members of the family (for instance, non-offending parents) and of the social network (peers). Such an approach is likely to optimize the support they are willing to give to teenagers and in turn sustain the recovery process of survivors of sexual abuse.

\section{Collaborations}

M Hébert, F Lavoie and M Blais participated equally in all stages of preparation of the article.

\section{Acknowledgments}

This research was supported by a grant from the Canadian Institutes of Health Research (CIHR). The authors wish to thank the school personnel and all the teenagers that participated in the study. Our thanks are also extended to Nataliya Dragieva for database management and statistical analyses as well as Catherine Moreau and Manon Robichaud for assistance in preparation of the manuscript. 


\section{References}

1. Stoltenborgh M, Van IJzendoorn MH, Euser EM, Bakermans-Kranenburg MJ. A global perspective on child sexual abuse: Meta-analysis of prevalence around the world. Child Maltreatment 2011; 16(2):79101.

2. Maniglio R. The impact of child sexual abuse on health: a systematic review of reviews. Clin Psychol Rev 2009; 29(7):647-657.

3. Walsh K, Fortier MA, DiLillo D. Adult coping with childhood sexual abuse: A theoretical and empirical review. Aggression and Violent Behaviour 2010; 15(1):1-13.

4. Zink T, Klesges L, Stevens S, Decker P. The development of a sexual abuse severity score: Characteristics of childhood sexual abuse associated with trauma symptomatology, somatization, and alcohol abuse. Journal of Interpersonal Violence 2009; 24(3):537-546.

5. Fergusson DM, Boden JM, Horwood LJ. Exposure to childhood sexual and physical abuse and adjustment in early adulthood. Child Abuse \& Neglect 2008; 32(6):607-619.

6. Fergusson DM, Horwood LJ, Woodward LJ. The stability of child abuse reports: A longitudinal study of the reporting behaviour of young adults. Psychological Medicine 2000; 30(3):529-544.

7. Brabant M-E, Hébert M, Chagnon F. Les symptômes dépressifs, les idéations et les tentatives suicidaires chez les adolescents ayant vécu une agression sexuelle. In: Hébert M, Cyr M, Tourigny M, organizadores. L'agression sexuelle envers les enfants. Tome II. Québec: Presses de l'Université du Québec; 2012. p. 55-89.

8. Daigneault I, Hébert M, Tourigny M. Attributions and coping in sexually abused adolescents referred for group treatment. Journal of Child Sexual Abuse 2006; 15(3):35-59.

9. Hébert M, Paradis A, Brabant M-E. Symptom clusters in sexually abused teenage girls. No prelo 2013.

10. Fernet M, Hébert M, Gascon S, Lacelle C. Agression sexuelle et comportements sexuels à risque à l'adolescence. In: Hébert M, Cyr M, Tourigny M, organizadores. L'agression sexuelle envers les enfants. Tome II. Québec: Presses de l'Université du Québec; 2012. p. 131-170.

11. Martin G, Bergen H, Richardson AS, Roeger L, Allison S. Sexual abuse and suicidality: Gender differences in a large community sample of adolescents. Child Abuse \& Neglect 2004; 28(5):491-503.

12. Hébert M, Daigneault I, Van Camp T. Agression sexuelle et risque de revictimisation à l'adolescence: Modèles conceptuels et défis liés à la prévention. In: Hébert $\mathrm{M}$, Cyr $\mathrm{M}$, Tourigny $\mathrm{M}$, éditeurs. L'agression sexuelle envers les enfants. Tome II. Québec: Presses de l'Université du Québec; 2012. p. 171-223

13. Hébert M, Lavoie F, Vitaro F, McDuff P, Tremblay RE. Association of child sexual abuse and dating victimization with mental health disorder in a sample of adolescent girls. Journal of Traumatic Stress 2008; 21(2):181-189.
14. Paolucci EO, Genuis ML, Violato C. A meta-analysis of the published research on the effects of child sexual abuse. Journal of Psychology 2001; 135(1):17-36.

15. Nooner KB, Linares LO, Batinjane J, Kramer RA, Silva R, Cloitre M. Factors related to posttraumatic stress disorder in adolescence. Trauma, Violence, \& Abuse 2012; 13(3):153-166.

16. Kendall-Tackett KA, Williams LM, Finkelhor D. Impact of sexual abuse on children: A review and synthesis of recent empirical studies. Psychological Bulletin 1993; 113(1):164-180.

17. Molnar BE, Buka SL, Kessler RC. Child sexual abuse and subsequent psychopathology: Results from the National Comorbidity Survey. Am J Public Health 2001; 91(5):753-760.

18. Boney-McCoy S, Finkelhor D. Prior victimization: A risk factor for child sexual abuse and for PTSDrelated symptomatology among sexually abused youth. Child Abuse \& Neglect 1995; 19(12):1401-1421.

19. Wolfe DA, Sas L, Wekerle C. Factors associated with the development of posttraumatic stress disorder among child victims of sexual abuse. Child Abuse of Neglect 1994; 18(1):37-50.

20. Connor KM, Davidson JRT. Development of a new resilience scale: The Connor-Davidson Resilience Scale (CD-RISC). Depression and Anxiety 2003; 18(2):76-82.

21. Elliot AN, Carnes CN. Reactions of non-offending parents to the sexual abuse of the children: A review of the literature. Child Mistreatment 2001; 6(4): 314-331.

22. Lovett BB. Child sexual abuse disclosure: Maternal response and other variables impacting the victim. Child and Adolescent Social Work Journal 2004; 21(4):355-371.

23. Rosenthal S, Feiring C, Taska L. Emotional support and adjustment over a year's time following sexual abuse discovery. Child Abuse \& Neglect 2003; 27(6): 641-661.

24. Thériault C, Cyr M, Wright J. Facteurs contextuels associés aux symptômes d'adolescentes victimes d'agression sexuelle intrafamiliale. Child Abuse of Neglect 2003; 27(11):1291-1309.

25. Bal S, De Bourdeaudhuij I, Crombez G, Van Oost P. Predictors of trauma symptomatology in sexually abused adolescents. Journal of Interpersonal Violence 2005; 20(11):1390-1405.

26. Buist KL, Dekoviæ M, Prinzie P. Sibling relationship quality and psychopathology of children and adolescents: A meta-analysis. Clin Psychol Rev 2013; 33(1):97-106.

27. Jenkins J. Sibling relationships in disharmonious homes: Potential difficulties and protective effects. In: Boer F, Dunn J, organizadores. Children's sibling relationships: Developmental and clinical issues. Hillsdale: Lawrence Erlbaum Associates Inc; 1992. p. 125-138.

28. Gass K, Jenkins J, Dunn J. Are sibling relationships protective? A longitudinalstudy. Journal of Child Psychology and Psychiatry 2007; 48(2):167-175. 
29. Caya ML, Liem JH. The role of sibling support in high-conflict families. Am J Orthopsychiatry 1998; 68(2):327-333.

30. Hébert M, Tremblay C, Parent N, Daignault IV, Piché C. Correlates of behavioral outcomes in sexually abused children. Journal of Family Violence 2006; 21(5):287-299.

31. Haskett ME, Nears K, Sabourin Ward C, McPherson AV. Diversity in adjustment of maltreated children: Factors associated with resilient functioning. Clin Psychol Rev 2006; 26(6):796-812.

32. Priebe G, Svedin CG. Child sexual abuse is largely hidden from the adult society - An epidemiological study of adolescents' disclosures. Child Abuse \& Neglect 2008; 32(12):1095-1108.

33. Nelis SM, Rae G. Peer attachment in adolescents. J Adolesc 2009; 32(2):443-447.

34. Feiring C, Taska L, Lewis M. The role of shame and attributional style in children's and adolescents' adaptation to sexual abuse. Child Maltreatment 1998; 3(2):129-142.

35. Parent-Boursier C, Hébert M. La perception de la relation père-enfant et l'adaptation des enfants suite au dévoilement d'une agression sexuelle. Revue canadienne des sciences du comportement, 2010; 42(3): 168-176.

36. Finkelhor D, Hotaling G, Lewis IA, Smith C. Sexual abuse in a national survey of adult men and women: Prevalence, characteristics, and risk factors. Child Abuse \& Neglect 1990; 14(1):19-28.

37. Tourigny M, Hébert M, Joly J, Cyr M, Baril K. Prevalence and co-occurrence of violence against children in the Quebec population. Aust N Z J Public Health 2008; 32(4):331-335.

38. Cohen JA, Bukstein O, Walter H, Benson SR, Chrisman A, Farchione TR, Hamilton J, Keable H, Kinlan J, Schoettle U, Siegel M, Stock S, Medicus J; AACAP Work Group On Quality Issues sues. Practice parameter for the assessment and treatment of children and adolescents with posttraumatic stress disorder. Journal of the American Academy of Child o Adolescent Psychiatry, 2010; 49(4):414-430.

39. Steinberg AM, Brymer MJ, Decker KB, Pynoos RS. The University of California at Los Angeles Posttraumatic Stress Disorder Reaction Index. Current Psychiatry Reports 2004; 6(2):96-100.

40. Vaishnavi S, Connor K, Davidson JRT. An abbreviated version of the Connor-Davidson Resilience Scale (CD-RISC), the CD-RISC2: Psychometric properties and applications in psychopharmacological trials. Psychiatry Research 2007; 152(2-3):293297.
41. Banyard VL, Cross C. Consequences of teen dating violence: Understanding intervening variables in ecological context. Violence Against Women 2008; 14(9):998-1013.

42. Aubin J, Lavallée C, Camirand J, Audet N, Beauvais B, Berthiaume P. Enquête sociale et de santé auprès des enfants et des adolescents québécois 1999. Québec: Institut de la statistique du Québec; 2002.

43. Kilpatrick DG, Ruggiero KJ, Acierno R, Saunders BE, Resnick HS, Best CL. Violence and risk of PTSD, major depression, substance abuse/dependence, and comorbidity: Results from the National Survey of Adolescents. J Consult Clin Psychol 2003; 71(4): 692-700.

44. Tolin DF, Foa EB. Sex differences in trauma and posttraumatic stress disorder: A quantitative review of 25 years of research. Psychological Bulletin 2006; 132(6):959-992.

45. Maikovich AK, Koenen KC, Jaffee SR. Posttraumatic stress symptoms and trajectories in child sexual abuse victims: An analysis of sex differences using the National Survey of Child and Adolescent WellBeing. J Abnorm Child Psychol 2009; 37(5):727-737.

46. Furman W, Buhrmester D. Age and sex differences in perceptions of networks of personal relationships. Child Development 1992; 63(1):103-115.

47. Lynch M, Cicchetti D. Children's relationships with adults and peers: An examination of elementary and junior high school students. Journal of School Psychology 1997; 35(1):81-99.

48. Hyman SM, Gold SN, Cott MA. Forms of social support that moderate PTSD in childhood sexual abuse survivors. Journal of Family Violence 2003; 18(5):295-300.

Artigo apresentado em 03/09/2013

Aprovado em 11/10/2013

Versão final apresentada em 22/10/2013 